\title{
Mortality risk stratification in isolated severe traumatic brain injury using the revised cardiac risk index
}

\author{
Maximilian Peter Forssten ${ }^{1,2}$. Gary Alan Bass ${ }^{1,3} \cdot$ Kai-Michael Scheufler $^{4,5} \cdot$ Ahmad Mohammad Ismail $^{1,2} \cdot$ Yang Cao $^{6}$. \\ Niels Douglas Martin ${ }^{3}$ Babak Sarani ${ }^{7}$ Shahin Mohseni ${ }^{1,2}$
}

Received: 7 October 2021 / Accepted: 10 November 2021 / Published online: 27 November 2021

(c) The Author(s) 2021

\begin{abstract}
Purpose Traumatic brain injury (TBI) continues to be a significant cause of mortality and morbidity worldwide. As cardiovascular events are among the most common extracranial causes of death after a severe TBI, the Revised Cardiac Risk Index (RCRI) could potentially aid in the risk stratification of this patient population. This investigation aimed to determine the association between the RCRI and in-hospital deaths among isolated severe TBI patients.

Methods All adult patients registered in the TQIP database between 2013 and 2017 who suffered an isolated severe TBI, defined as a head AIS $\geq 3$ with an AIS $\leq 1$ in all other body regions, were included. Patients were excluded if they had a head AIS of 6 . The association between different RCRI scores $(0,1,2,3, \geq 4)$ and in-hospital mortality was analyzed using a Poisson regression model with robust standard errors while adjusting for potential confounders, with RCRI 0 as the reference. Results 259,399 patients met the study's inclusion criteria. RCRI 2 was associated with a $6 \%$ increase in mortality risk [adjusted IRR (95\% CI) $1.06(1.01-1.12), p=0.027$ ], RCRI 3 was associated with a 17\% increased risk of mortality [adjusted IRR (95\% CI) $1.17(1.05-1.31), p=0.004]$, and RCRI $\geq 4$ was associated with a $46 \%$ increased risk of in-hospital mortality [adjusted IRR(95\% CI) 1.46 (1.11-1.90), $p=0.006$ ], compared to RCRI 0.

Conclusion An elevated RCRI $\geq 2$ is significantly associated with an increased risk of in-hospital mortality among patients with an isolated severe traumatic brain injury. The simplicity and bedside applicability of the index makes it an attractive choice for risk stratification in this patient population.
\end{abstract}

Keywords Traumatic brain injury $\cdot$ Revised Cardiac Risk Index $\cdot$ Risk stratification $\cdot$ Mortality

Shahin Mohseni

mohsenishahin@yahoo.com; shahin.mohseni@oru.se

Maximilian Peter Forssten

maximilian.forssten@oru.se

Gary Alan Bass

gary.bass@pennmedicine.upenn.edu

Kai-Michael Scheufler

kai-michael.scheufler@regionorebrolan.se

Ahmad Mohammad Ismail

amzenik@gmail.com

Yang Cao

yang.cao@oru.se

Niels Douglas Martin

niels.martin@pennmedicine.upenn.edu

Babak Sarani

bsarani@mfa.gwu.edu
1 School of Medical Sciences, Orebro University, 70281 Örebro, Sweden

2 Division of Trauma and Emergency Surgery, Orebro University Hospital, 70185 Örebro, Sweden

3 Division of Traumatology, Surgical Critical Care and Emergency Surgery, University of Pennsylvania, Philadelphia, PA 19104, USA

4 Department of Neurosurgery, Orebro University Hospital, 70185 Örebro, Sweden

5 Medical School, Heinrich-Heine University Dusseldorf, Düsseldorf, Germany

6 Clinical Epidemiology and Biostatistics, School of Medical Sciences, Orebro University, Örebro, Sweden

7 Division of Trauma and Acute Care Surgery, George Washington University School of Medicine \& Health Sciences, Washington, DC, USA 


\section{Introduction}

Traumatic brain injury (TBI) continues to be a significant cause of mortality and morbidity worldwide, with at least one-third of all injury-related deaths in the United States carrying a diagnosis of traumatic brain injury [1-7]. Globally, 69 million individuals are estimated to suffer a TBI every year, with approximately 60,000 individuals in the United States and 82,000 individuals in Europe suffering a TBI-related death annually [4, 8, 9]. Particularly among people under the age of 45 , TBI is a leading cause of death; however, the highest rates of TBI-related hospitalizations are actually seen among older individuals, particularly those over the age of $75[4,6]$. In this age group, the rate of TBI-related deaths were estimated to be as high as 77.0 per 100,000 in the United States in 2017, while the corresponding rate was $\leq 15.1$ among individuals under the age of 45 [4]. Risk stratification might therefore be an essential tool for the management of this patient population, allowing the early identification of patients with an excess risk of deterioration, death, or other adverse outcomes, and facilitating the distribution of healthcare resources and expertise with greater efficiency. With the contention that cardiovascular events are among the most common extracranial causes of death after a severe TBI, the Revised Cardiac Risk Index (RCRI) may be one contender for this role [10-14].

The RCRI has previously been used to predict the 30-day risk of postoperative myocardial infarction, cardiac arrest, and all-cause mortality [15, 16]. It makes use of only six independent variables: congestive heart failure, ischemic heart disease, cerebrovascular disease, preoperative serum creatinine level above $177 \mu \mathrm{mol} / \mathrm{L}(2 \mathrm{mg} / \mathrm{dL})$, diabetes mellitus requiring insulin therapy, and high-risk surgery $[15,16]$. Previous studies have demonstrated a clear association between an increase in the RCRI score and excess mortality as well as other adverse outcomes in many non-cardiac surgical procedures [17-21]. Its utility in TBI patients has hitherto not been as thoroughly studied. This investigation aimed to determine the association between the RCRI and in-hospital deaths among isolated severe TBI patients. The hypothesis was that those with an elevated cardiac risk index would exhibit a higher incidence of in-hospital mortality.

\section{Methods}

The need for approval by the institutional review board was waived for this study since it only made use of retrospective anonymized data. The Declaration of Helsinki and the Strengthening the Reporting of Observational Studies in Epidemiology (STROBE) guidelines were adhered to throughout its completion [22]. All data were obtained from the American College of Surgeons Trauma Quality Improvement Program (TQIP) database, a national multi-institutional database of all trauma patients collected from more than 850 participating trauma centers across the United States. This database is gathered for risk-adjusted benchmarking and quality improvement. Furthermore, well-trained data registrars amass more than 100 patientrelated and center-related variables. The TQIP plays a central role in the development of evidence-based interventions to enhance patient quality of care by looking at the enrolled centers' performances [23]. These included patient age, sex, race, initial Glasgow Coma Scale (GCS) in the emergency room (ER), intracranial injuries, abbreviated injury scale (AIS) for each region, surgical interventions, comorbidities, length of stay and in-hospital mortality. All adult patients ( 18 years or older) registered in the TQIP database between 2013 and 2017 who suffered an isolated severe traumatic brain injury (sTBI) were considered for inclusion. An isolated sTBI was defined as a head AIS $\geq 3$ with an AIS $\leq 1$ in all other regions. Patients were excluded if they had a head AIS of 6 since these injuries are generally considered non-survivable.

\section{Calculation of the RCRI}

The RCRI was calculated according to Lindenauer et al., which has previously been used in other surgical subspecialties [19-21, 24]. This included the variables congestive heart failure, ischemic heart disease, cerebrovascular disease, renal insufficiency, diabetes mellitus, and high-risk surgery [24]. The RCRI was based on the total number of these factors present in each patient. Both chronic kidney disease and acute kidney injury were included in the definition of renal insufficiency. High-risk surgery was defined as all intraperitoneal, intrathoracic, intracranial, and suprainguinal vascular procedures, according to the 2014 American College of Cardiology/American Heart Association Guideline on Perioperative Cardiovascular Evaluation and Management of Patients Undergoing Noncardiac Surgery [25].

\section{Statistical analysis}

As described by previous studies investigating the RCRI, patients were divided into five cohorts: RCRI 0, RCRI 1, RCRI 2, RCRI 3, and RCRI $\geq 4$ [19-21, 24]. Patients' demographics and clinical features were compared between these cohorts. All continuous variables were presented as a median and interquartile range since they were non-normally distributed. The Kruskall-Wallis test was used to determine the statistical significance of differences between the cohorts. 
Categorical variables are described as counts and percentages, with comparisons using the Chi-square test or Fisher's exact test. The primary outcome was in-hospital mortality.

Poisson regression analysis was employed to analyze the association between the RCRI and in-hospital mortality. A Poisson regression model with robust standard errors was used while adjusting for age, sex, race, initial GCS in the ER, AIS in the head, neck, spine, thorax, abdomen, upper extremity, and lower extremity, as well as comorbidities and neurosurgical interventions. Results are presented as an incident rate ratio (IRR) and 95\% confidence interval (CI). Multiple imputation by chained equations was used to manage missing values.

Statistical significance was defined as a two-sided $p$-value $<0.05$. Analyses were performed using the statistical programming language R (R Foundation for Statistical Computing, Vienna, Austria) [26].

\section{Results}

After applying the inclusion and exclusion criteria, 259,399 patients remained for further analysis. Patients with an elevated RCRI tended to be significantly older (RCRI $\geq 4$ : 74 years vs RCRI 0: 58 years, $p<0.001$ ), were more likely to racially identify as black (RCRI $\geq 4: 15.6 \%$ vs RCRI 0 : $10.6 \%, p<0.001$ ), and presented with a higher initial GCS in the ER (RCRI $\geq 4$, GCS $14-15: 74.6 \%$ vs RCRI 0, GCS $14-15: 69.9 \%, p<0.001)$. Accordingly, traumatic subdural hematomas were more prevalent among patients with an elevated RCRI (RCRI $\geq 4: 79.8 \%$ vs. RCRI 0: $61.6 \%$, $p<0.001$ ), while cerebral contusions and epidural hematomas decreased in prevalence. A higher proportion of patients with an elevated RCRI also underwent a neurosurgical intervention (RCRI $\geq 416.8 \%$ vs RCRI 0: $12.9 \%, p<0.001$ ) (Table 1). Nearly all comorbidities increased in prevalence with an increasing RCRI score, which is consistent with expectations and confirms TQIP's internal validity (Table 2). Length of stay tended to increase with a higher RCRI score (RCRI $\geq 4: 6$ days vs. RCRI 0: 3 days, $p<0.001$ ). Serial clinically significant increases in crude in-hospital mortality were observed among patients with an increasing RCRI, with an inflection point observed at RCRI $\geq 2$ (RCRI $\geq 4$ : $20.2 \%$ vs. RCRI $0: 11.2 \%, p<0.001$ ) (Table 3 ).

After adjusting for potential confounders in the Poisson regression analysis, the same pattern was observed. Compared to patients with RCRI 0 , only patients with an RCRI $\geq 2$ were observed to have an increased mortality risk. RCRI 2 was associated with a $6 \%$ increase in mortality risk [adjusted IRR (95\% CI) $1.06(1.01-1.12), p=0.027$ ], RCRI 3 was associated with a $17 \%$ increased risk of mortality [adjusted IRR (95\% CI) 1.17 (1.05-1.31), $p=0.004$ ], and $\mathrm{RCRI} \geq 4$ was associated with a $46 \%$ increased risk of in-hospital mortality [adjusted IRR (95\% CI) 1.46 (1.11-1.90), $p=0.006]$, compared to RCRI 0. RCRI 1 was not associated with an increase in the risk of mortality [adjusted IRR (95\% CI) $0.98(0.95-1.01), p=0.199]$ (Table 4).

\section{Discussion}

This is the first study to date investigating the association between the RCRI and in-hospital mortality among patients who suffered an isolated sTBI. As could be observed from crude in-hospital mortality, patients with an RCRI $\geq 2$ have an increased risk of in-hospital mortality. The adjusted Poisson regression model confirms this association and further demonstrates that this association remains after adjusting for age, sex, race, initial GCS, severity of the intracranial injury, other underlying comorbidities, and neurosurgical interventions.

An RCRI score of 2 is associated with a $6 \%$ increase in the risk of in-hospital mortality, while the risk increases to $17 \%$ and $46 \%$ at an RCRI score of 3 and $\geq 4$, respectively. This threshold is consistent with the American College of Cardiology's and American Heart Association's definition of elevated cardiac risk as well as previous research into the utility of the RCRI in patients undergoing an elective resection for colonic tumors [21, 25]. In contrast, previous research into the RCRI's applicability in hip fractures has demonstrated a stepwise increase in mortality risk for each additional point on the RCRI $[18,19]$. This can likely be explained by the high degree of frailty in the hip fracture population due to advanced age and higher prevalence of comorbidities [18, 19, 27-29]. sTBI patients are comparatively younger and have a lower comorbidity burden, as seen in the current data.

Extracranial organ dysfunctions are common among patients with severe TBI, with cardiovascular dysfunction being among the most frequent $[10,12,13]$. Patients with a TBI have been shown to have an almost three-fold increased risk of major adverse cardiovascular events, including heart failure, arrhythmia, myocardial infarction and cardiac necrosis [11]. Accordingly, cardiovascular adverse events are the most common extracranial causes of death in TBI patients $[10,14]$. Several studies have shown an association between beta-blocker use and decreased mortality in patients suffering from TBI [30-32], leading to a recommendation for this therapy in this population by the Eastern Association for the Surgery of Trauma [33]. This finding has been attributed to the cardioprotective effect of beta-blockers in response to the hyperadrenergic state often seen in this patient population. In hip fracture patients, where cardiovascular deaths are the most common cause of postoperative mortality [34], an interaction between RCRI and beta-blocker treatment could 
Table 1 Patient demographics and clinical features after an isolated TBI

\begin{tabular}{|c|c|c|c|c|c|c|}
\hline & $\begin{array}{l}\text { RCRI 0 } \\
(N=187,442)\end{array}$ & $\begin{array}{l}\text { RCRI } 1 \\
(N=55,792)\end{array}$ & $\begin{array}{l}\text { RCRI } 2 \\
(N=13,346)\end{array}$ & $\begin{array}{l}\text { RCRI } 3 \\
(N=2473)\end{array}$ & $\begin{array}{l}\mathrm{RCRI} \geq 4 \\
(N=346)\end{array}$ & $p$-value \\
\hline Age, median [IQR] & $58[37-76]$ & $74[63-82]$ & $75[67-82]$ & $75[67-82]$ & $74[66-81]$ & $<0.001$ \\
\hline Sex, $n(\%)$ & & & & & & $<0.001$ \\
\hline Female & $65,945(35.2)$ & $22,368(40.1)$ & $5241(39.3)$ & $928(37.5)$ & $131(37.9)$ & \\
\hline Male & $121,444(64.8)$ & $33,408(59.9)$ & $8104(60.7)$ & $1545(62.5)$ & $215(62.1)$ & \\
\hline Missing & $53(0.0)$ & $16(0.0)$ & $1(0.0)$ & $0(0.0)$ & $0(0.0)$ & \\
\hline \multicolumn{7}{|l|}{ Race, $n(\%)$} \\
\hline White & $142,685(76.1)$ & 44,011 (78.9) & $10,363(77.6)$ & $1840(74.4)$ & $255(73.7)$ & $<0.001$ \\
\hline Black & $19,805(10.6)$ & $5032(9.0)$ & $1444(10.8)$ & 344 (13.9) & 54 (15.6) & $<0.001$ \\
\hline Asian & $4646(2.5)$ & $1784(3.2)$ & $409(3.1)$ & $80(3.2)$ & $8(2.3)$ & $<0.001$ \\
\hline American Indian & $2082(1.1)$ & $469(0.8)$ & $93(0.7)$ & $21(0.8)$ & $2(0.6)$ & $<0.001$ \\
\hline Pacific islander & $482(0.3)$ & $158(0.3)$ & $48(0.4)$ & $10(0.4)$ & $1(0.3)$ & 0.105 \\
\hline Other & $13,353(7.1)$ & $3397(6.1)$ & $823(6.2)$ & $151(6.1)$ & $22(6.4)$ & $<0.001$ \\
\hline Missing & $3720(2.0)$ & $821(1.5)$ & $143(1.1)$ & $22(0.9)$ & $4(1.2)$ & \\
\hline Initial GCS in the ER, $n(\%)$ & & & & & & $<0.001$ \\
\hline Mild (GCS 14-15) & $130,965(69.9)$ & $40,792(73.1)$ & $9624(72.1)$ & $1774(71.7)$ & $258(74.6)$ & \\
\hline Moderate (GCS 9-13) & $16,676(8.9)$ & $4991(8.9)$ & $1306(9.8)$ & $247(10.0)$ & $33(9.5)$ & \\
\hline Severe (GCS 3-8) & $31,096(16.6)$ & 6954 (12.5) & $1626(12.2)$ & 314 (12.7) & 40 (11.6) & \\
\hline Missing & $8,705(4.6)$ & $3055(5.5)$ & $790(5.9)$ & $138(5.6)$ & $15(4.3)$ & \\
\hline \multicolumn{7}{|l|}{ Intracranial injury, $n(\%)$} \\
\hline Cerebral contusion & $46,545(24.8)$ & $12,080(21.7)$ & $2735(20.5)$ & $514(20.8)$ & $66(19.1)$ & $<0.001$ \\
\hline Epidural hematoma & $9747(5.2)$ & $1522(2.7)$ & $353(2.6)$ & $60(2.4)$ & $11(3.2)$ & $<0.001$ \\
\hline Traumatic subdural hematoma & $115,452(61.6)$ & $41,580(74.5)$ & $10,269(76.9)$ & $1943(78.6)$ & $276(79.8)$ & $<0.001$ \\
\hline Traumatic subarachnoid hemorrhage & $55,424(29.6)$ & $15,877(28.5)$ & $3494(26.2)$ & $661(26.7)$ & $100(28.9)$ & $<0.001$ \\
\hline Diffuse axonal injury & $2478(1.3)$ & $615(1.1)$ & $112(0.8)$ & $16(0.6)$ & $7(2.0)$ & $<0.001$ \\
\hline Other intracranial injury & $11,358(6.1)$ & $2214(4.0)$ & $446(3.3)$ & $97(3.9)$ & $18(5.2)$ & $<0.001$ \\
\hline Head AIS, $n(\%)$ & & & & & & $<0.001$ \\
\hline 3 & $100,464(53.6)$ & $26,823(48.1)$ & $6135(46.0)$ & $1090(44.1)$ & $146(42.2)$ & \\
\hline 4 & $47,823(25.5)$ & $15,583(27.9)$ & $3601(27.0)$ & $682(27.6)$ & $105(30.3)$ & \\
\hline 5 & $39,155(20.9)$ & $13,386(24.0)$ & $3610(27.0)$ & $701(28.3)$ & $95(27.5)$ & \\
\hline Neck AIS, $n(\%)$ & & & & & & $<0.001$ \\
\hline Injury not present & $185,818(99.1)$ & $55,478(99.4)$ & $13,265(99.4)$ & $2463(99.6)$ & $344(99.4)$ & \\
\hline 1 & $1624(0.9)$ & $314(0.6)$ & $81(0.6)$ & $10(0.4)$ & $2(0.6)$ & \\
\hline Thorax AIS, $n(\%)$ & & & & & & $<0.001$ \\
\hline Injury not present & $180,282(96.2)$ & $53,992(96.8)$ & $12,943(97.0)$ & $2403(97.2)$ & $336(97.1)$ & \\
\hline 1 & $7160(3.8)$ & $1800(3.2)$ & $403(3.0)$ & $70(2.8)$ & $10(2.9)$ & \\
\hline Abdomen AIS, $n(\%)$ & & & & & & $<0.001$ \\
\hline Injury not present & $183,403(97.8)$ & $54,849(98.3)$ & $13,118(98.3)$ & $2424(98.0)$ & $331(95.7)$ & \\
\hline 1 & $4039(2.2)$ & $943(1.7)$ & $228(1.7)$ & $49(2.0)$ & $15(4.3)$ & \\
\hline Spine AIS, $n(\%)$ & & & & & & $<0.001$ \\
\hline Injury not present & $185,107(98.8)$ & $55,169(98.9)$ & $13,253(99.3)$ & $2455(99.3)$ & $346(100.0)$ & \\
\hline 1 & $2335(1.2)$ & $623(1.1)$ & $93(0.7)$ & $18(0.7)$ & $0(0.0)$ & \\
\hline Upper extremity AIS, $n(\%)$ & & & & & & $<0.001$ \\
\hline Injury not present & $164,697(87.9)$ & $49,522(88.8)$ & $11,897(89.1)$ & $2219(89.7)$ & $293(84.7)$ & \\
\hline 1 & $22,745(12.1)$ & $6270(11.2)$ & $1449(10.9)$ & $254(10.3)$ & $53(15.3)$ & \\
\hline Lower extremity AIS, $n(\%)$ & & & & & & $<0.001$ \\
\hline Injury not present & $170,339(90.9)$ & $51,126(91.6)$ & $12,239(91.7)$ & $2277(92.1)$ & $313(90.5)$ & \\
\hline 1 & $17,103(9.1)$ & $4666(8.4)$ & $1107(8.3)$ & $196(7.9)$ & $33(9.5)$ & \\
\hline Neurosurgical intervention, $n(\%)$ & $24,160(12.9)$ & $8744(15.7)$ & $2116(15.9)$ & $444(18.0)$ & $58(16.8)$ & $<0.001$ \\
\hline High risk surgery ${ }^{\mathrm{a}}, n(\%)$ & $0(0.0)$ & $2794(5.0)$ & $939(7.0)$ & $275(11.1)$ & $54(15.6)$ & $<0.001$ \\
\hline
\end{tabular}

$T B I$ traumatic brain injury, RCRI Revised Cardiac Risk Index, IQR interquartile range, GCS Glasgow Coma Scale, ER emergency room, AIS abbreviated injury score

${ }^{a}$ High-risk surgery is defined as all intraperitoneal, intrathoracic, and suprainguinal vascular procedures 
Table 2 Comorbidities in isolated TBI patients

\begin{tabular}{|c|c|c|c|c|c|c|}
\hline & $\begin{array}{l}\text { RCRI } 0 \\
(N=187,442)\end{array}$ & $\begin{array}{l}\text { RCRI } 1 \\
(N=55,792)\end{array}$ & $\begin{array}{l}\text { RCRI } 2 \\
(N=13,346)\end{array}$ & $\begin{array}{l}\text { RCRI } 3 \\
(N=2,473)\end{array}$ & $\begin{array}{l}\mathrm{RCRI} \geq 4 \\
(N=346)\end{array}$ & $p$-value \\
\hline Hypertension, $n(\%)$ & $62,092(33.1)$ & $39,904(71.5)$ & $10,518(78.8)$ & $1993(80.6)$ & $284(82.1)$ & $<0.001$ \\
\hline Myocardial infarction, $n(\%)$ & $0(0.0)$ & 2077 (3.7) & $1926(14.4)$ & $777(31.4)$ & $211(61.0)$ & $<0.001$ \\
\hline Congestive heart failure, $n(\%)$ & $0(0.0)$ & $6082(10.9)$ & $5465(40.9)$ & $1753(70.9)$ & $306(88.4)$ & $<0.001$ \\
\hline Peripheral vascular disease, $n(\%)$ & $870(0.5)$ & $860(1.5)$ & $443(3.3)$ & $132(5.3)$ & $27(7.8)$ & $<0.001$ \\
\hline Cerebrovascular disease, $n(\%)$ & $0(0.0)$ & $7584(13.6)$ & $4702(35.2)$ & $1194(48.3)$ & $245(70.8)$ & $<0.001$ \\
\hline Dementia, $n(\%)$ & $11,352(6.1)$ & $6359(11.4)$ & $1679(12.6)$ & $300(12.1)$ & $41(11.8)$ & $<0.001$ \\
\hline COPD, $n(\%)$ & $9949(5.3)$ & $6,007(10.8)$ & $2,258(16.9)$ & $493(19.9)$ & $88(25.4)$ & $<0.001$ \\
\hline Liver cirrhosis, $n(\%)$ & $2312(1.2)$ & $1113(2.0)$ & $283(2.1)$ & $53(2.1)$ & $9(2.6)$ & $<0.001$ \\
\hline Diabetes mellitus, $n(\%)$ & $0(0.0)$ & $34,774(62.3)$ & $10,602(79.4)$ & $2186(88.4)$ & $332(96.0)$ & $<0.001$ \\
\hline Coagulopathy, $n(\%)$ & $14,620(7.8)$ & $11,020(19.8)$ & $3804(28.5)$ & $760(30.7)$ & $111(32.1)$ & $<0.001$ \\
\hline Chronic kidney disease, $n(\%)$ & $0(0.0)$ & $1815(3.3)$ & $2576(19.3)$ & $1057(42.7)$ & $223(64.5)$ & $<0.001$ \\
\hline Acute kidney injury, $n(\%)$ & $0(0.0)$ & $576(1.0)$ & $431(3.2)$ & $153(6.2)$ & $26(7.5)$ & $<0.001$ \\
\hline $\begin{array}{l}\text { Currently receiving chemotherapy for } \\
\text { cancer, } n(\%)\end{array}$ & $1089(0.6)$ & $496(0.9)$ & $94(0.7)$ & $16(0.6)$ & $1(0.3)$ & $<0.001$ \\
\hline Metastatic carcinoma, $n(\%)$ & $1947(1.0)$ & $1012(1.8)$ & $243(1.8)$ & $46(1.9)$ & $7(2.0)$ & $<0.001$ \\
\hline
\end{tabular}

$T B I$, traumatic brain injury; RCRI, Revised Cardiac Risk Index; COPD, chronic obstructive pulmonary disease

Table 3 Crude outcomes in isolated TBI patients

\begin{tabular}{llllll}
\hline & $\begin{array}{l}\text { RCRI 0 } \\
(N=187,442)\end{array}$ & $\begin{array}{l}\text { RCRI 1 } \\
(N=55,792)\end{array}$ & $\begin{array}{l}\text { RCRI 2 } \\
(N=13,346)\end{array}$ & $\begin{array}{l}\text { RCRI 3 } \\
(N=2473)\end{array}$ & $\begin{array}{l}\text { RCRI } \geq 4 \\
(N=346)\end{array}$ \\
\hline Length of stay, median [IQR] & $3.0[2.0-6.0]$ & $4.0[2.0-8.0]$ & $5.0[3.0-9.0]$ & $5.0[3.0-11]$ & $6.0[3.0-13]$ \\
Missing, $n(\%)$ & $2966(1.6)$ & $793(1.4)$ & $183(1.4)$ & $43(1.7)$ & $5(1.4)$ \\
In-hospital mortality, $n(\%)$ & $20,902(11.2)$ & $6352(11.4)$ & $1882(14.1)$ & $436(17.6)$ & $70(20.2)$ \\
Missing & $26(0.0)$ & $0(0.0)$ & $0(0.0)$ & $0(0.0)$ & $0(0.0)$ \\
\hline
\end{tabular}

$T B I$ traumatic brain injury, RCRI Revised Cardiac Risk Index, ER emergency room

Table 4 IRRs for in-hospital mortality after an isolated TBI

\begin{tabular}{lll}
\hline & IRR $(95 \% \mathrm{CI})$ & $p$-value \\
\hline RCRI & & \\
0 & Ref & \\
1 & $0.98(0.95-1.01)$ & 0.199 \\
2 & $1.06(1.01-1.12)$ & 0.027 \\
3 & $1.17(1.05-1.31)$ & 0.004 \\
$\geq 4$ & $1.46(1.11-1.90)$ & 0.006 \\
\hline
\end{tabular}

Poisson regression model with robust standard errors adjusted for age, sex, race, initial GCS in the ER, AIS, comorbidities, and neurosurgical intervention. Multiple imputation by chained equations was used to manage missing values

$I R R$ incident rate ratio, TBI traumatic brain injury, $R C R I$ Revised Cardiac Risk Index, GCS Glasgow Coma Scale, ER emergency room, $A I S$ abbreviated injury score, COPD chronic obstructive pulmonary disease be noticed with a more pronounced effect of such treatment with an increased RCRI score [35]. Future studies could potentially help identify the subgroup of sTBI patients that, based on their cardiac risk calculated with the RCRI, benefit the most from beta-blockade.

The current study results indicate that TBI patients' comorbidity burden, as summarized by the RCRI, can be used to stratify patients based on their risk of in-hospital mortality. In the past, other risk scoring systems have been used in the context of TBI patients, including the Charlson Comorbidity Index (CCI) and the APACHE II score [36-40]. Even risk calculators such as Predictive OpTimal Trees in Emergency Surgery Risk (POTTER) could be considered a possible alternative [41, 42]. However, each of these indexes have their limitations. The included variables inherently constrain the APACHE II score, which requires both the results of several blood tests as well as patient vitals, and makes it challenging to apply in the emergency setting [43]. Furthermore, both the CCI and APACHE II require a substantial number of variables, which are incorporated into intricate 
formulae, to arrive at a final score; this further limits their utility in the acute management of patients [43-45]. POTTER, while demonstrating a substantial predictive ability, also requires the results of several blood tests as well as access to the mobile application to be used [43-45]. The RCRI instead only uses six variables, which can be assessed quickly after a patient arrives in the ER. This simplicity will likely reduce the index's predictive ability, compared to the other prediction models, but is also key to it being a pointof-care risk stratification tool of some utility in TBI patients.

These characteristics make the RCRI an appealing choice as part of the decision-making process in patients suffering an isolated sTBI. As can be seen in Tables 1 and 2, there is a large degree of heterogeneity among sTBI patients. While the majority of sTBI patients suffer from a relatively low number of comorbidities, those with an elevated RCRI exhibit a significantly higher disease burden, even after excluding the comorbidities included in the RCRI. The proportion of patients with, for example, COPD or a coagulopathy was more than 4 times higher in patients with RCRI $\geq 4$ compared to those with RCRI 0 . Even the rate of metastatic carcinoma doubled from the lowest RCRI score to the highest. These TBI patients should reasonably be expected to require a different management strategy compared to their healthier counterparts. Using the RCRI, these high risk patients may be identified early on which could allow for a more efficient allocation of expertise and resources [46]. It could also enable the quantification of risk for patients and family members to aid them in participating in the decision making process around critical care, operative interventions, and even goals-of-care [47, 48].

It is also worth mentioning the role of race in the calculation of the RCRI. Previous studies have shown that the traditional formulas for calculating the estimated glomerular filtration rate have tended to underestimate the prevalence of chronic kidney disease in black patients [49-51]. As a result, there is a risk of underestimating the presence of renal insufficiency in this portion of the population. However, in the current study we were able to adjust for race among several other factors. Even after this adjustment, the association between an RCRI score and increased in-hospital mortality remained.

As with all retrospective studies, the current analysis is subject to several limitations. First and foremost, all analyses were restricted to the data available in the TQIP dataset. No adjustments could be made for any potential confounder that was not already registered. The cause of death was also unknown; however, this was of lesser significance as the RCRI includes all-cause mortality among its potential outcomes [16]. This study was also reliant on the accuracy of the data registered in the dataset in order to correctly categorize patients. It is therefore important that the results are interpreted judiciously as this study only provides evidence for an associative relationship between the RCRI and mortality. The RCRI does not include added morbidity or mortality related to intracranial operations and thus may underestimate the overall risk of death in patients with sTBI who require operative intervention. Prospective studies are required to establish a causal relationship, including added morbidity/mortality due to operative intervention, when using the RCRI in reaching treatment decisions. The analysis was also limited to patients with an isolated sTBI, so caution is warranted when considering the results in the context of polytrauma patients with concomitant TBIs. The fact that patients with an RCRI score $\leq 1$ still had an in-hospital mortality rate around $11 \%$ also indicates that other factors, such as frailty and disease severity, may also need to be considered in order to more fully understand and predict mortality in this patient population, as has been seen when predicting deaths in other traumatic injuries [52].

\section{Conclusion}

An elevated RCRI $\geq 2$ is significantly associated with an increased risk of in-hospital mortality among isolated TBI patients. The simplicity and bedside applicability of the index makes it an attractive choice for risk stratification in this patient population. However, further studies are required to determine if there is a causal relationship as well as how it can most effectively be used.

Author contributions MF, GAB, and SM conceived the idea and drafted the manuscript. MF and YC performed an analysis of the data. MF, GAB, KMS, AMI, YC, BS, NDM, and SM participated in the manuscript's critical review and final approval.

Funding Open access funding provided by Örebro University. No financial support or funding was received for the presented work.

\section{Declarations}

Conflict of interest The authors have no conflicts of interest to disclose.

Open Access This article is licensed under a Creative Commons Attribution 4.0 International License, which permits use, sharing, adaptation, distribution and reproduction in any medium or format, as long as you give appropriate credit to the original author(s) and the source, provide a link to the Creative Commons licence, and indicate if changes were made. The images or other third party material in this article are included in the article's Creative Commons licence, unless indicated otherwise in a credit line to the material. If material is not included in the article's Creative Commons licence and your intended use is not permitted by statutory regulation or exceeds the permitted use, you will need to obtain permission directly from the copyright holder. To view a copy of this licence, visit http://creativecommons.org/licenses/by/4.0/. 


\section{References}

1. Maas AIR, Menon DK, Adelson PD, Andelic N, Bell MJ, Belli A, et al. Traumatic brain injury: integrated approaches to improve prevention, clinical care, and research. Lancet Neurol. 2017;16:987-1048.

2. Corrigan JD, Selassie AW, Orman JA. The epidemiology of traumatic brain injury. J Head Trauma Rehabil. 2010;25:72-80.

3. Faul M, Coronado V. Chapter 1 - Epidemiology of traumatic brain injury. In: Grafman J, Salazar AM, editors. Handbook of Clinical Neurology [Internet]. Elsevier; 2015. p. 3-13. Available from: https://www.sciencedirect.com/science/article/pii/ B9780444528926000015. Accessed 17 Sep 2021

4. Centers for Disease Control and Prevention. Surveillance Report of Traumatic Brain Injury-related Hospitalizations and Deaths by Age Group, Sex, and Mechanism of Injury [Internet]. United States: Centers for Disease Control and Prevention, U.S. Department of Health and Human Services; 2021. Report No.: 2016 and 2017. Available from: https://www.cdc.gov/traum aticbraininjury/pdf/TBI-surveillance-report-2016-2017-508. pdf. Accessed 17 Sept 2021

5. QuickStats: Injury and Traumatic Brain Injury (TBI)-Related Death Rates, by Age Group-United States, 2006* [Internet]. Available from: https://www.cdc.gov/mmwr/preview/mmwrh tml/mm5910a9.html. Accessed 17 Sep 2021

6. Popescu C, Anghelescu A, Daia C, Onose G. Actual data on epidemiological evolution and prevention endeavours regarding traumatic brain injury. J Med Life. 2015;8:272-7.

7. Kureshi N, Erdogan M, Thibault-Halman G, Fenerty L, Green RS, Clarke DB. Long-term trends in the epidemiology of major traumatic brain injury. J Commun Health. 2021. https://doi.org/ 10.1007/s 10900-021-01005-Z.

8. Dewan MC, Rattani A, Gupta S, Baticulon RE, Hung Y-C, Punchak M, et al. Estimating the global incidence of traumatic brain injury. J Neurosurg. 2018;130:1080-97.

9. Majdan M, Plancikova D, Brazinova A, Rusnak M, Nieboer $\mathrm{D}$, Feigin V, et al. Epidemiology of traumatic brain injuries in Europe: a cross-sectional analysis. Lancet Public Health. 2016;1:e76-83.

10. Astarabadi M, Khurrum M, Asmar S, Bible L, Chehab M, Castanon $\mathrm{L}$, et al. The impact of non-neurological organ dysfunction on outcomes in severe isolated traumatic brain injury. J Trauma Acute Care Surg. 2020;89:405-10.

11. Eric Nyam T-T, Ho C-H, Chio C-C, Lim S-W, Wang J-J, Chang $\mathrm{C}-\mathrm{H}$, et al. Traumatic brain injury increases the risk of major adverse cardiovascular and cerebrovascular events: a 13-year population-based study world. Neurosurgery. 2019;122:e740-53.

12. Robba C, Bonatti G, Pelosi P, Citerio G. Extracranial complications after traumatic brain injury: targeting the brain and the body. Curr Opin Crit Care. 2020;26:137-46.

13. Krishnamoorthy V, Komisarow JM, Laskowitz DT, Vavilala MS. Multiorgan dysfunction after severe traumatic brain injury: epidemiology, mechanisms, and clinical management. Chest. 2021;160:956-64.

14. Kemp CD, Johnson JC, Riordan WP, Cotton BA. How we die: the impact of nonneurologic organ dysfunction after severe traumatic brain injury. Am Surg. 2008;74:866-72.

15. Lee TH, Marcantonio ER, Mangione CM, Thomas EJ, Polanczyk CA, Cook EF, et al. Derivation and prospective validation of a simple index for prediction of cardiac risk of major noncardiac surgery. Circulation. 1999;100:1043-9.

16. Duceppe E, Parlow J, MacDonald P, Lyons K, McMullen M, Srinathan $\mathrm{S}$, et al. Canadian cardiovascular society guidelines on perioperative cardiac risk assessment and management for patients who undergo noncardiac surgery. Can J Cardiol. 2017;33:17-32.

17. Ford MK, Beattie WS, Wijeysundera DN. Systematic review: prediction of perioperative cardiac complications and mortality by the revised cardiac risk index. Ann Intern Med. 2010;152:26-35.

18. Forssten MP, Mohammad Ismail A, Sjolin G, Ahl R, Wretenberg $\mathrm{P}$, Borg T, et al. The association between the revised cardiac risk index and short-term mortality after hip fracture surgery. Eur J Trauma Emerg Surg. 2020. https://doi.org/10.1007/ s00068-020-01488-w.

19. Forssten MP, Mohammad Ismail A, Borg T, Ahl R, Wretenberg $\mathrm{P}, \mathrm{Cao} \mathrm{Y}$, et al. Postoperative mortality in hip fracture patients stratified by the revised cardiac risk index: a Swedish nationwide retrospective cohort study. Trauma Surg Acute Care Open. 2021;6:e000778.

20. Bass GA, Forssten M, Pourlotfi A, Ahl Hulme R, Cao Y, Matthiessen $\mathrm{P}$, et al. Cardiac risk stratification in emergency resection for colonic tumours. BJS Open. 2021. https://doi.org/10.1093/bjsop en/zrab057.

21. Hulme RA, Forssten MP, Pourlotfi A, Cao Y, Bass GA, Matthiessen $\mathrm{P}$, et al. The association between revised cardiac risk index and postoperative mortality following elective colon cancer surgery: a retrospective nationwide cohort study. Scand J Surg. 2021. https:// doi.org/10.1177/14574969211037588.

22. WMA-The World Medical Association-WMA Declaration of Helsinki-Ethical Principles for Medical Research Involving Human Subjects [Internet]. Available from: https://www.wma. net/policies-post/wma-declaration-of-helsinki-ethical-principlesfor-medical-research-involving-human-subjects/. Accessed 21 Sep 2020

23. Trauma Quality Improvement Program (TQIP) [Internet]. American College of Surgeons. Available from: http://www.facs.org/ quality-programs/trauma/tqp/center-programs/tqip. Accessed 01 Nov 2021

24. Lindenauer PK, Pekow P, Wang K, Mamidi DK, Gutierrez B, Benjamin EM. Perioperative beta-blocker therapy and mortality after major noncardiac surgery. N Engl J Med. 2005;353:349-61.

25. Fleisher LA, Fleischmann KE, Auerbach AD, Barnason Susan A, Beckman Joshua A, Bozkurt B, et al. ACC/AHA guideline on perioperative cardiovascular evaluation and management of patients undergoing noncardiac surgery. Circulation. 2014;2014(130):278-333.

26. R Development Core Team. R: A Language and Environment for Statistical Computing [Internet]. Vienna, Austria: R Foundation for Statistical Computing; 2008. Available from: http://www.Rproject.org/. Accessed 22 Sept 2020

27. Gundel O, Thygesen LC, Gögenur I, Ekeloef S. Postoperative mortality after a hip fracture over a 15 -year period in Denmark: a national register study. Acta Orthop. 2020;91:58-62.

28. Cher EWL, Allen JC, Howe TS, Koh JSB. Comorbidity as the dominant predictor of mortality after hip fracture surgeries. Osteoporos Int. 2019;30:2477-83.

29. Choi HG, Lee YB, Rhyu SH, Kwon BC, Lee JK. Mortality and cause of death postoperatively in patients with a hip fracture: a national cohort longitudinal follow-up study. Bone Joint J. 2018;100:436-42.

30. Mohseni S, Talving P, Wallin G, Ljungqvist O, Riddez L. Preinjury $\beta$-blockade is protective in isolated severe traumatic brain injury. J Trauma Acute Care Surg. 2014;76:804-8.

31. Khalili H, Ahl R, Paydar S, Sjolin G, Cao Y, Abdolrahimzadeh Fard H, et al. Beta-blocker therapy in severe traumatic brain injury: a prospective randomized controlled trial. World J Surg. 2020;44:1844-53.

32. Ley EJ, Leonard SD, Barmparas G, Dhillon NK, Inaba K, Salim A, et al. Beta blockers in critically ill patients with traumatic brain injury: results from a multicenter, prospective, observational 
American association for the surgery of trauma study. J Trauma Acute Care Surg. 2018;84:234-44.

33. Alali AS, Mukherjee K, McCredie VA, Golan E, Shah PS, Bardes $\mathrm{JM}$, et al. Beta-blockers and traumatic brain injury: a systematic review and meta-analysis. Ann Surg. 2017;266:952-61.

34. Ahl R, Mohammad Ismail A, Borg T, Sjölin G, Forssten MP, Cao Y, et al. A nationwide observational cohort study of the relationship between beta-blockade and survival after hip fracture surgery. Eur J Trauma Emerg Surg. 2021. https://doi.org/10.1007/ s00068-020-01588-7.

35. Ismail AM, Ahl R, Forssten MP, Cao Y, Wretenberg P, Borg T, et al. The interaction between per-admission $\beta$-blocker therapy, the revised cardiac risk index, and mortality in geriatric hip fracture patients. J Trauma Acute Care Surg. 2021. https://doi.org/10.1097/ TA.0000000000003358.

36. Peck KA, Calvo RY, Sise CB, Johnson J, Yen JW, Sise MJ, et al. Death after discharge: predictors of mortality in older braininjured patients. J Trauma Acute Care Surg. 2014;77:978-83.

37. Utomo WK, Gabbe BJ, Simpson PM, Cameron PA. Predictors of in-hospital mortality and 6-month functional outcomes in older adults after moderate to severe traumatic brain injury. Injury. 2009;40:973-7.

38. Gürsoy G, Gürsoy C, Kuşcu Y, Gümüş DS. APACHE II or INCNS to predict mortality in traumatic brain injury: a retrospective cohort study. Ulus Travma Acil Cerrahi Derg. 2020;26:893-8.

39. Nik A, Sheikh Andalibi MS, Ehsaei MR, Zarifian A, Ghayoor Karimiani E, Bahadoorkhan G. The efficacy of Glasgow coma scale (GCS) score and acute physiology and chronic health evaluation (APACHE) II for predicting hospital mortality of ICU patients with acute traumatic brain injury. Bull Emerg Trauma. 2018;6:141-5.

40. Nyam T-TE, Aoee K-H, Hung S-Y, Shen M-L, Yu T-C, Kuo J-R. Four score predicts early outcome in patients after traumatic brain injury. Neurocrit Care. 2017;26:225-31.

41. El Hechi MW, Nour Eddine SA, Maurer LR, Kaafarani HMA. Leveraging interpretable machine learning algorithms to predict postoperative patient outcomes on mobile devices. Surgery. 2021;169:750-4.

42. Hechi MWE, Maurer LR, Levine J, Zhuo D, Moheb ME, Velmahos GC, et al. Validation of the artificial intelligence-based predictive optimal trees in emergency surgery risk (POTTER) calculator in emergency general surgery and emergency laparotomy patients. J Am Coll Surg. 2021;232:912-9.

43. Knaus WA, Draper EA, Wagner DP, Zimmerman JE. APACHE II: a severity of disease classification system. Crit Care Med. 1985;13:818-29.

44. Charlson ME, Pompei P, Ales KL, MacKenzie CR. A new method of classifying prognostic comorbidity in longitudinal studies: development and validation. J Chronic Dis. 1987;40:373-83.

45. Bertsimas D, Dunn J, Velmahos GC, Kaafarani HMA. Surgical risk is not linear: derivation and validation of a novel, userfriendly, and machine-learning-based predictive optimal trees in emergency surgery risk (POTTER) calculator. Ann Surg. 2018;268:574-83.

46. Mohseni S, Joseph B, Peden CJ. Mitigating the stress response to improve outcomes for older patients undergoing emergency surgery with the addition of beta-adrenergic blockade. Eur J Trauma Emerg Surg. 2021. https://doi.org/10.1007/s00068-021-01647-7.

47. Adeleke I, Chae C, Okocha O, Sweitzer BJ. Risk assessment and risk stratification for perioperative complications and mitigation: Where should the focus be? How are we doing? Best Practice and Research: Clin Anaesthesiol [Internet]. 2020. Available from: http://www.scopus.com/inward/record.url?scp=85097414592\& partnerID=8YFLogxK. Accessed 16 Sep 2021

48. Stahel PF, Douglas IS, VanderHeiden TF, Weckbach S. The history of risk: a review. World J Emerg Surg. 2017;12:15.

49. Delanaye P, Mariat C, Maillard N, Krzesinski J-M, Cavalier E. Are the creatinine-based equations accurate to estimate glomerular filtration rate in African American populations? CJASN Am Soc Nephrol. 2011;6:906-12.

50. Delanaye P, Mariat C. The applicability of eGFR equations to different populations. Nat Rev Nephrol. 2013;9:513-22.

51. Flamant M, Vidal-Petiot E, Metzger M, Haymann J-P, Letavernier E, Delatour V, et al. Performance of GFR estimating equations in African Europeans: basis for a lower race-ethnicity factor than in African Americans. Am J Kidney Dis. 2013;62:182-4.

52. Cao Y, Forssten MP, Mohammad Ismail A, Borg T, Ioannidis I, Montgomery S, et al. Predictive values of preoperative characteristics for 30-day mortality in traumatic hip fracture patients. J Pers Med. 2021;11:353. 